\title{
Fifteen species in one: deciphering the Brachionus plicatilis species complex (Rotifera, Monogononta) through DNA taxonomy
}

\author{
Scott Mills $\cdot$ J. Arturo Alcántara-Rodríguez $\cdot$ Jorge Ciros-Pérez $•$ \\ Africa Gómez - Atsushi Hagiwara - Kayla Hinson Galindo • Christian D. Jersabek • \\ Reza Malekzadeh-Viayeh · Francesca Leasi · Jae-Seong Lee • \\ David B. Mark Welch • Spiros Papakostas • Simone Riss • \\ Hendrik Segers $\cdot$ Manuel Serra $\cdot$ Russell Shiel $\cdot$ Radoslav Smolak • \\ Terry W. Snell • Claus-Peter Stelzer • Cuong Q. Tang • \\ Robert L. Wallace • Diego Fontaneto $\cdot$ Elizabeth J. Walsh
}

Received: 7 December 2015/Revised: 15 February 2016/Accepted: 28 February 2016/Published online: 5 April 2016

(C) Springer International Publishing Switzerland 2016

\begin{abstract}
Understanding patterns and processes in biological diversity is a critical task given current and rapid environmental change. Such knowledge is even more essential when the taxa under consideration are important ecological and evolutionary models. One of these cases is the monogonont rotifer cryptic species complex Brachionus plicatilis, which is by far the
\end{abstract}

Guest editors: M. Devetter, D. Fontaneto, C. D. Jersabek, D. B. Mark Welch, L. May \& E. J. Walsh / Evolving rotifers, evolving science

Diego Fontaneto and Elizabeth J. Walsh have contributed equally to this work.

Electronic supplementary material The online version of this article (doi:10.1007/s10750-016-2725-7) contains supplementary material, which is available to authorized users.

S. Mills

James Cook University, 1 James Cook Drive,

Townsville 4811, Australia

J. Arturo Alcántara-Rodríguez · J. Ciros-Pérez Proyecto de Investigación en Limnología Tropical, FES Iztacala, Universidad Nacional Autónoma de México, Mexico City, Mexico

\section{A. Gómez}

School of Biological, Biomedical and Environmental Sciences, University of Hull, Hull HU6 7RX, UK most extensively studied group of rotifers, is widely used in aquaculture, and is known to host a large amount of unresolved diversity. Here we collate a dataset of previously available and newly generated sequences of COI and ITS1 for 1273 isolates of the $B$. plicatilis complex and apply three approaches in DNA taxonomy (i.e. ABGD, PTP, and GMYC) to identify and provide support for the existence of 15 species within the complex. We used these results to explore phylogenetic signal in morphometric and ecological traits, and to understand correlation among the traits using phylogenetic comparative models. Our results support niche conservatism for some traits (e.g. body length) and phylogenetic plasticity for others (e.g. genome size).

\author{
A. Hagiwara \\ Graduate School of Fisheries and Environmental \\ Sciences, Nagasaki University, Nagasaki 852-8521, Japan \\ K. H. Galindo · E. J. Walsh \\ Department of Biological Sciences, University of Texas at \\ El Paso, El Paso, USA \\ C. D. Jersabek \\ Department of Organismal Biology, University of \\ Salzburg, 5020 Salzburg, Austria
}


Keywords Biodiversity - COI - Cryptic species · Evolution · ITS1 - Phylogenetic comparative methods $\cdot$ Zooplankton

\section{Introduction}

The occurrence of complexes of cryptic speciesgroups of species that are not confidently distinguishable based only on morphology_has become widely recognised in biodiversity analyses (Knowlton, 1993; Bickford et al., 2007). The revolution brought by efficient DNA sequencing technologies has driven an explosion of studies on biodiversity, unmasking hidden morphological diversity and revealing that cryptic species are common and widespread across all animal phyla (Pfenninger \& Schwenk, 2007; Trontelj $\&$ Fiser, 2009). While deciphering hidden diversity in species complexes remains a taxonomic challenge, it is crucial to address important questions in speciation research to understand patterns and processes in biodiversity (Butlin et al., 2009).

Phylum Rotifera is one of several phyla with a high level of cryptic diversity (Fontaneto et al., 2009; García-Morales \& Elías-Gutiérrez, 2013; Gabaldón et al., 2016). Cryptic diversity is expected in rotifers, due to the small size of these animals, the paucity of

R. Malekzadeh-Viayeh

Artemia and Aquatic Research Institute, Urmia

University, Urmia, Iran

F. Leasi

Department of Invertebrate Zoology, Smithsonian

National Museum of Natural History, Washington, DC, USA

\section{J.-S. Lee}

Department of Biological Science, College of Science, Sungkyunkwan University, Suwon 16419, South Korea

\section{B. Mark Welch}

Josephine Bay Paul Center for Comparative Molecular Biology and Evolution, Marine Biological Laboratory, Woods Hole, MA, USA

\section{S. Papakostas}

Division of Genetics and Physiology, Department of Biology, University of Turku, Turku, Finland

S. Riss · C.-P. Stelzer

Research Institute for Limnology, University of Innsbruck, 5310 Mondsee, Austria taxonomically relevant morphological features, and the scarcity of rotifer taxonomists (Wallace et al., 2006). Moreover, the reliance of rotifers on chemical communication in species recognition (Snell, 1998) may contribute to the prevalence of morphological cryptic diversity. One clear example of cryptic diversity in the phylum is the species complex Brachionus plicatilis Müller, 1786, a cosmopolitan taxon with an affinity for saline environments. Here we report an extensive study undertaken to unravel the hidden diversity within this species complex.

Two morphotypes of $B$. plicatilis were reported as early as the 19th century when Ehrenberg ascribed the name Brachionus muelleri Ehrenberg, 1834, as distinct from the first record for the species complex, B. plicatilis (although the former name is now considered a junior synonym of the latter). A modern discussion of diversity in B. plicatilis began when two strains with differing morphological and ecological characteristics were recognised as the L (large) and S (small) types (Oogami, 1976). From the early 1980s, it became increasingly clear that the morphological and genetic differences between the $\mathrm{L}$ and $\mathrm{S}$ strains supported the hypothesis that the two morphotypes should be recognised as separate species. Serra \& Miracle (1983) noted marked seasonal cyclomorphosis in individuals from Spanish water bodies commenting

H. Segers

OD Nature, Royal Belgian Institute of Natural Sciences, 1000 Brussels, Belgium

M. Serra

Institut Cavanilles de Biodiversitat i Biologia Evolutiva, Universitat de València, 46071 Valencia, Spain

R. Shiel

Biological Sciences, University of Adelaide, Adelaide, SA 5005, Australia

R. Smolak

Department of Ecology, Faculty of Humanities and Natural Sciences, Presov University, 08116 Presov, Slovakia

T. W. Snell

School of Biology, Georgia Institute of Technology, Atlanta, GA 30332-0230, USA

C. Q. Tang

Department of Life Sciences, The Natural History Museum, Cromwell Road, London SW7 5BD, UK 
that, while $B$. plicatilis populations were thought to exhibit high levels of phenotypic plasticity in their natural habitat, laboratory clones founded from single individuals could be readily distinguished biometrically. They also noted a good correlation between biometric classification and spatial distribution of wild populations, hypothesising that some of their clones may constitute a "well-differentiated genetic race".

The idea of discriminatory genetic structure within what was considered a single species was further supported by Snell \& Carrillo (1984) who examined 13 strains of B. plicatilis sourced globally, concluding that strain identity was the most important deterministic factor of size. Serra \& Miracle (1987) supported these observations, reporting that size in B. plicatilis populations seemed to be largely under genetic control. Furthermore, these authors noted that size could be defined to a narrow range of biometric deviations at different salinities and temperatures. In the same year, King \& Zhao (1987) reported a substantial amount of genetic variation in three enzyme loci between clones established from individuals collected at different times from Soda Lake, Nevada (USA). Other phenotypic traits provided evidence for distinct species. For example, some members of the species complex retain their resting eggs within the body, while others employ a thin thread to hold them outside their body (Serrano et al., 1989).

The existence of cryptic species within $B$. plicatilis was reinforced by Fu et al. (1991a), who examined 67 isolates from around the globe and showed that they could be clearly classified into large (L) and small (S) morphotypes based upon morphometric analysis alone. In a second study, the same group clearly discriminated between $\mathrm{L}$ and $\mathrm{S}$ strains on a genetic basis and concluded that at least two species existed (Fu et al., 1991b). Additional evidence for the existence of at least two species within the taxon came from the examination of chromosomes: $\mathrm{L}$ and $\mathrm{S}$ morphotypes have karyotypes of $2 n=22$ and $2 n=25$, respectively (Rumengan et al., 1991,

\section{R. L. Wallace}

Department of Biology, Ripon College, Ripon, USA

D. Fontaneto $(\square)$

Institute of Ecosystem Study, National Research Council of Italy, 28922 Verbania Pallanza, Italy

e-mail: d.fontaneto@ise.cnr.it
1993). The size discontinuities between $\mathrm{L}$ and $\mathrm{S}$ morphotypes were shown to correspond to behavioural reproductive isolation between these groups (Snell \& Hawkinson, 1983). Snell (1989) showed how male mate recognition could be used as a means of establishing species boundaries in monogonont rotifers in this case. Both Fu et al. (1993) and Gómez \& Serra (1995) also identified reproductive isolation between the $\mathrm{L}$ and $\mathrm{S}$ types based on male mating behaviour. Thus, in reviewing morphological, behavioural, and genetic studies, Segers (1995) concluded that the $\mathrm{L}$ and $\mathrm{S}$ strains could be defined as two distinct species, namely B. plicatilis sensu stricto (s.s.) and Brachionus rotundiformis Tschugunoff, 1921, respectively.

Further investigations by Gómez \& Serra (1995), Gómez et al. (1995), Gómez \& Snell (1996), Serra et al. (1998), and Ortells et al. (2000) using molecular markers and reproductive isolation tests revealed that several cryptic species could be ascribed to both $B$. plicatilis and $B$. rotundiformis. This revelation culminated in a paper by Ciros-Pérez et al. (2001a) that used morphological, ecological, and genetic differences to support B. plicatilis s.s. and B. rotundiformis and to introduce a medium size type, designated SM, to the species complex with the description of Brachionus ibericus Ciros-Pérez, Gómez \& Serra, 2001. At this stage, three groups were known: L with B. plicatilis s.s., SM with B. ibericus, and SS (here so called with two capital ' $\mathrm{s}$ ' to be clearly differentiated from the $\mathrm{S}$ strains) with $B$. rotundiformis (Fig. 1).

A phylogenetic analysis of mitochondrial and nuclear gene sequences (namely COI and ITS1) on a worldwide dataset supported an ancient differentiation of this rotifer lineage into at least nine species, often sympatric, which were clustered into the morphologically recognised L, SM, and SS morphotypes (Gómez et al., 2002). Suatoni et al. (2006) suggested the existence of 14-16 species across the three clades, based on DNA sequence data and the high degree of concordance between genealogical and reproductive isolation (based on experimental trials). Supporting this diversity, genetic and phenotypic data were then used to describe two additional species: Brachionus manjavacas Fontaneto, Giordani, Melone \& Serra, 2007, within the L type (Fontaneto et al., 2007) and Brachionus koreanus Hwang, Dahms, Park \& Lee, 2013 within the SM type (Hwang et al., 2013). Finally, another species, already described as Brachionus 
Fig. 1 Photomicrographs of three representative lineages of the Brachionus plicatilis species complex. $\mathbf{A}, \mathbf{B}, \mathbf{C}$ ) dorsal view; D, E, F) lateral view; $\mathbf{G}, \mathbf{H}, \mathbf{I}$ ) ventral view. A, D, G Large strain, clone BUSCL (clade L1 in Figs. 2-5); B, E,

$\mathbf{H}$ Medium strain, clone MULCL (clade SM4); C, F, I) Small strain, clone TOWCL (clade SS1). Scale bar $=100 \mu \mathrm{m}$

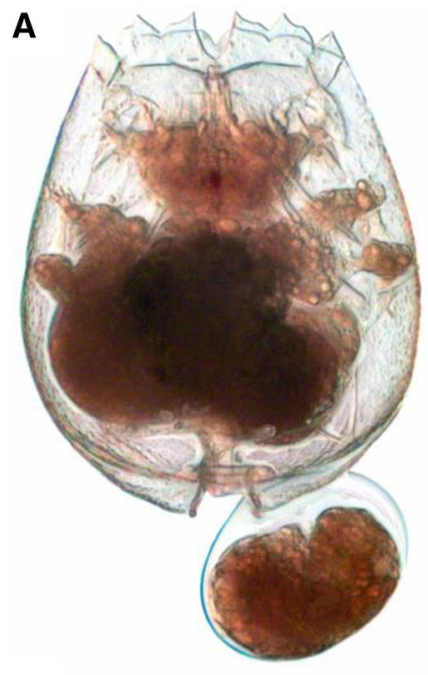

B
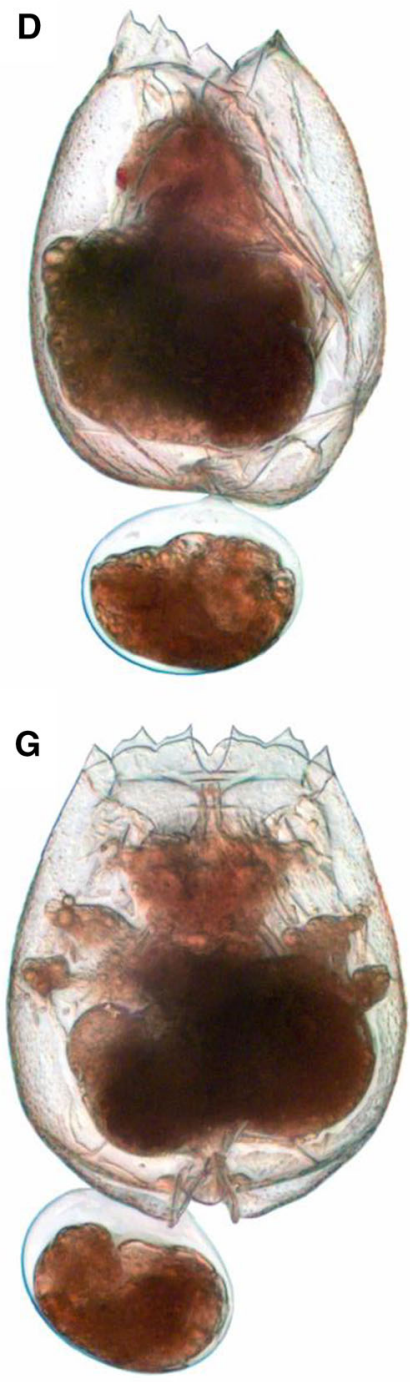

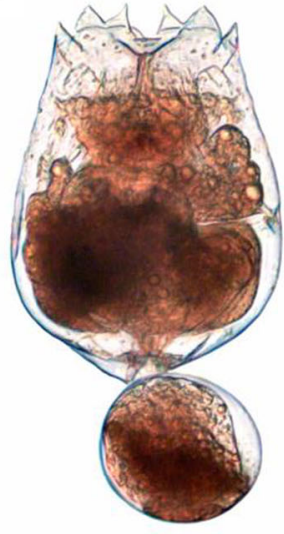

C

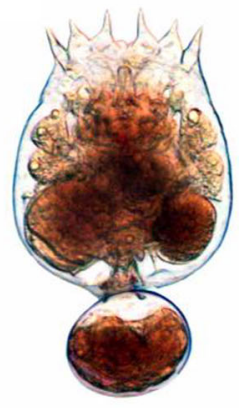

E

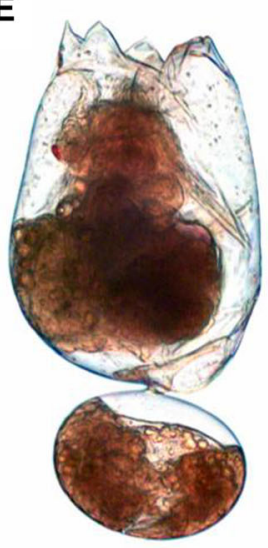

H

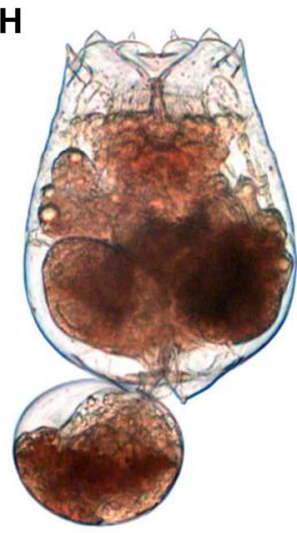

$\mathbf{F}$

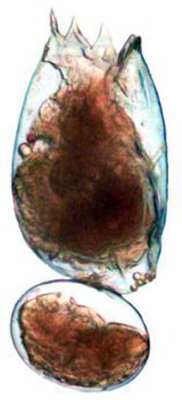

I

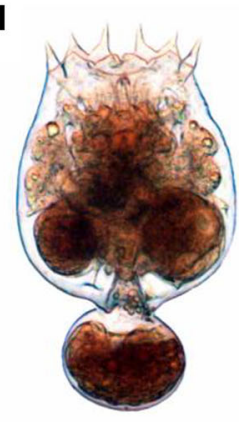


asplanchnoidis Charin, 1947, were known to be a member of the group (Kutikova, 1970; Segers, 1995; Jersabek \& Bolortsetseg, 2010); however, no DNA sequences could be unambiguously attributed to it.

Thus, a sizable amount of analyses using molecular, morphological, ecological, and reproductive isolation suggests that there are many putative species within the B. plicatilis complex. However, only six species have been formally described (in chronological order): B. plicatilis s.s., B. rotundiformis, B. asplanchnoidis, B. ibericus, B. manjavacas, and B. koreanus, respectively, by Müller (1786), Tschungunoff (1921), Charin (1947), Ciros-Pérez et al. (2001a), Fontaneto et al. (2007), and Hwang et al. (2013). Nevertheless, there are additional clades that may correspond to putative new species and that have been designated by the scientific community simply as "Brachionus sp. 'Locality'”, where 'Locality' refers to the place where the samples were first collected. Examples of this designation include Brachionus sp. 'Almenara' (Ortells et al., 2000; Gómez et al., 2002), Brachionus sp. 'Nevada' (Gómez et al., 2002), and Brachionus sp. 'Mexico' (Alcántara-Rodríguez et al., 2012).

In an effort to clarify the systematics of the B. plicatilis species complex, we present an analysis of the most extensive dataset on genetic diversity in the species complex. The first aim of our contribution is to provide a clear phylogenetic structure to support identification and designation of species in the complex through the use of several approaches in DNA taxonomy. Our second aim is to present a study of the evolutionary relationships among the species in the complex for a comparative analysis exploring the phylogenetic signal of biological traits and correlations among species-specific traits of the different species. The B. plicatilis species complex is by far the most extensively studied group of rotifers, and these animals have been used to investigate a wide variety of phenomena including ecological interactions (CirosPérez et al., 2001b, 2004, 2015; Montero-Pau et al., 2011; Gabaldon et al., 2015), toxicology (Serrano et al., 1986; Snell \& Persoone, 1989; Dahms et al., 2011), osmoregulation (Lowe et al., 2005), local adaptation (Campillo et al., 2009; Alcántara-Rodríguez et al., 2012), the evolution of sex (Carmona et al., 2009), phylogeography (Gómez et al., 2000, 2007; Mills et al., 2007), ageing (Snell et al., 2015), and evolutionary processes (Stelzer et al., 2011; Fontaneto et al., 2012; Tang et al., 2014a). In addition, due to the ease and low cost of producing highly dense cultures of these rotifers, members of this species complex have been widely used in aquaculture as a source of live feed for larval crustaceans and fishes (Fukusho, 1983; Watanabe et al., 1983; Lubzens \& Zmora, 2003). We make use of this information to provide a first assessment of the evolutionary trajectories of biological and ecological traits in the $B$. plicatilis species complex.

\section{Methods}

\section{Data collection}

We gathered all the DNA sequences for COI (Cytochrome Oxidase $c$ subunit I) and ITS1 (Internal Transcribed Spacer 1) from members of the B. plicatilis species complex that were available in GenBank in March 2015. To ensure the quality of the data, we removed short sequences (4 sequences shorter than $300 \mathrm{bp}$ were removed from the COI dataset), confirmed that the COI sequences lacked internal stop codons (given that NCBI did not do it automatically for the older sequences), investigated that the maximum uncorrected genetic difference among the sequences was less than $40 \%$, and verified that the best BLAST hit for each sequence was from a rotifer of the genus Brachionus. This resulted in the retention of $811 \mathrm{COI}$ and 184 ITS1 sequences. In addition, we sequenced COI and ITS1 from a total of 449 wild - caught individuals or existing lab strains, using DNA extraction and gene amplification protocols established for the species complex more than a decade ago (Gómez et al., 2002). The full list of 1273 isolates used for the study and the GenBank accession numbers of their COI and ITS1 sequences are provided in Supplementary File S1. All newly obtained sequences were deposited in GenBank with accession numbers from KU299052 to KU299752. We did not include sequences from clades 15 and 16 of Suatoni et al. (2006), as they seem to be outside the species complex, they have never been found again, no voucher or lab cultures exist, and no additional information is available for them.

In addition to DNA sequence data, we collected contextual data for all 1273 isolates, when available. These data included the name of the water body where they were found, the country and continent of 
collection (following the divisions of the Taxonomic Database Working Group, TDWG, by Brummitt, 2001), geographic coordinates, and habitat type (either coastal system or continental saltwater body). This was done by scanning the literature mentioning the isolates, and by searching through our personal records in the cases when the samples were originally collected by one of the authors. In addition to these ecological and geographical data, we included information on body length, genome size, either from the literature, or by measuring them specifically for this study.

\section{Phylogenetic reconstructions}

Analyses of the phylogenetic relationships among isolates of the B. plicatilis complex were performed on three datasets: COI, ITS1, and the concatenated COI + ITS1 dataset. For the three datasets, the analytical steps were the same and included alignment, selection of the best evolutionary model, and phylogenetic reconstructions through Maximum Likelihood (ML) and Bayesian Inference (BI). For the outgroup, we selected one isolate of the congeneric Brachionus calyciflorus Pallas, 1766 for which both COI and ITS1 existed (isolate XZ8: GU012801, GU232732, Xiang et al., 2011).

Alignments were straightforward for COI, whereas the most reliable alignment for ITS1 was obtained with MAFFT v6.814b using the Q-INS-I algorithm (regarded as the optimal strategy for ribosomal markers; Katoh et al., 2009). Alignments were trimmed at the ends for a total length of 661 positions for COI and 359 positions for ITS1. Alignments were reduced to unique sequences by collapsing all identical sequences into one single sequence. These unique sequences are similar to haplotypes, but may underestimate diversity because sequences of different lengths (and with gaps for ITS1) were collapsed into a single unique sequence if they were identical in the overlapping part. In those cases, we used the longest sequence for the purpose of phylogenetic reconstruction. In order to avoid ambiguities between COI and ITS1 unique sequences, we used different prefixes: we named unique sequences for $\mathrm{COI}$ as numbers with ' $\mathrm{H}$ ' as a prefix, and unique sequences for ITS 1 as numbers with ' $h$ ' as a prefix.

The most appropriate evolutionary model for the COI and the ITS 1 datasets was determined using
ModelGenerator v0.85 (Keane et al., 2006) independently for each marker. The best model was identified as $\mathrm{GTR}+\mathrm{G}+\mathrm{I}$ in both cases.

Maximum Likelihood reconstructions were performed with PhyML 3.0 (Guidon \& Gascuel, 2003) for the COI and ITS1 datasets. GTR $+\mathrm{G}+\mathrm{I}$ with 4 gamma categories was implemented as an evolutionary model; support values were estimated through approximate Likelihood Ratio Test, aLRT (Guidon \& Gascuel, 2003). For the concatenated dataset, RAxML v8 (Stamatakis, 2014) was used with default settings; the alignment was partitioned by gene and all parameters were estimated independently for each of the two partitions.

Bayesian Inference reconstructions were performed in BEAST v1.6.1 (Drummond et al., 2012) using the default settings except for: GTR $+\mathrm{G}+\mathrm{I}$ as the site model, an uncorrelated lognormal relaxed clock, a Yule speciation tree prior with lognormal distribution of birth rate, 100 million generations, and trees saved every 10,000 generations. Effective sample sizes (ESS) were checked in Tracer v1.5 (Rambaut et al., 2013), and the consensus tree was obtained in TreeAnnotator v1.6.1 with a $20 \%$ burnin. For the concatenated dataset, all parameters were estimated independently for each partition.

\section{DNA taxonomy}

Three methods of DNA taxonomy were used to identify putative species from DNA sequence data (Fontaneto et al., 2015). For all methods, the outgroup was excluded from the analyses. Consistency among methods and among the three datasets was considered as increased confidence in the identification of the species in the $B$. plicatilis complex. In case of discordance in the amount of splitting, we chose to keep the smallest number of entities, in order to avoid over-splitting the species complex; thus, if a mistake is made in the identification of taxa, it is made in the direction of being more conservative in the amount of cryptic diversity.

The Automatic Barcode Gap Discovery (ABGD) was applied independently to the COI and ITS1 alignments to test for the existence of a barcode gap in the genetic distances and then to identify groups of individuals united by shorter genetic distances than the gap. These groups were considered to be equivalent to species (Puillandre et al., 2012). ABGD was used 
through its online tool (http://wwwabi.snv.jussieu.fr/ public/abgd/abgdweb.html) with default settings. For COI, we considered only results obtained with prior intraspecific divergence higher than $1.5 \%$, given what is known in rotifers for this marker (Fontaneto, 2014); for ITS1, given that there is no previous knowledge of prior intraspecific divergence, we explored all the possible prior intraspecific divergences available in the default settings. The ABGD method, based on genetic distances calculated in one marker, was applied only to the alignments of the single markers and not to the concatenated alignment.

The Poisson Tree Process (PTP) was applied to the three ML trees (COI, ITS1, and CO1 + ITS) to search for evidence of independently evolving entities akin to species, optimising differences in branching patterns within and between species (Zhang et al., 2013). PTP was used through its online tool (http://species.h-its.org/ ) with default settings for all three analyses: the output is reported from its ML and BI optimisation algorithms.

The generalised mixed Yule coalescent (GMYC) model was applied to search for evidence of independently evolving entities akin to species, optimising the threshold between within-species coalescent processes and between-species Yule processes on the branching patterns (Fujisawa \& Barraclough, 2013). GMYC models were run on (i) the BEAST trees for the three alignments (COI, ITS, and CO1 + ITS), (ii) the ML trees made ultrametric (i.e. with branching patterns proportional to the evolutionary model and to time) through r8s using penalised likelihood and crossvalidation to choose the optimal smoothing parameter among 1, 10, and 100 (Sanderson, 2003), and (iii) ML trees made ultrametric through the chronoMLP and chronos functions in the R v 3.1.2 (R Core Team, 2014) package ape v 3.2 (Paradis et al., 2004). Parts (i) and (ii) were performed as recommended by Tang et al. (2014b). All GMYC models were run with the $\mathrm{R}$ package splits v 1.0-19 (Ezard et al., 2009).

Further hypothesis testing and validation

We used several approaches to support the hypothesis that the new taxa identified by DNA taxonomic methods represent species.

First, we made a direct comparison of our putative species with the species that are already described in the complex (i.e. B. asplanchnoidis, B. ibericus, B. koreanus, B. manjavacas, B. plicatilis s.s., and
B. rotundiformis). Our expectation was that species identified by DNA taxonomy would correspond to known species in the complex.

Second, we calculated uncorrected genetic distances between each pair of sequences in the alignments, and compared the distances within and among species with what is known in other rotifers and in animals in general. The expectation, in comparison to what is known in other rotifer species complexes, is to have a barcoding threshold in COI that is higher than the commonly accepted $3 \%$ for other animals (Hebert et al., 2003; Fontaneto, 2014).

Third, we checked whether the maximum genetic distances found in pairwise comparisons within each species were related to sample size (defined both as number of individuals and as number of unique sequences for each marker) for the same species. Given the possibility of a phylogenetic signal (Münkemüller et al., 2012) in the comparisons between species in the complex, we tested whether our data were phylogenetically structured using Pagel's lambda (Pagel, 1999) and Blomberg's K (Blomberg et al., 2003). We then used phylogenetic generalised least square (PGLS) analyses to account for the confounding factor of phylogenetic relatedness (Garamszegi, 2014). Values of Pagel's lambda and Blomberg's K of zero indicate no phylogenetic signal, which occurs when closely related species are not more similar than distantly related ones; values of one or higher indicate that closely related species are significantly more similar than expected (Kamilar \& Cooper, 2013). In PGLS, the phylogeny is used to account for phylogenetic pseudoreplication in the statistical models. As a phylogeny for the PGLS, we used the one obtained from RAxML + r8s on the combined alignment of COI + ITS1 dataset, randomly pruned to one single sequence per species, with branch length transformations (lambda, delta, and kappa) optimised by maximum likelihood given the data and the model. The combination RAxML + r8s was chosen because it gave the lowest number of species with the smallest confidence interval according to all of the DNA taxonomy methods (see Table 1). There is, of course, the possibility of methodological biases due to uncertainties in the phylogenetic reconstructions. Therefore, to provide further support for the results obtained from the combined dataset, we repeated the analyses also using the phylogenies obtained from the single markers (Supplementary File S2). Concordance in the 
Table 1 Results of the different methods of DNA taxonomy

\begin{tabular}{llll}
\hline $\begin{array}{l}\text { Method } \\
\text { Concatenated }\end{array}$ & COI & ITS1 & \\
\hline ABGD & 17 & 14 & NA \\
PTP ML & 52 & 14 & 51 \\
PTP BI & 55 & 14 & 51 \\
GMYC BEAST & $40(29-49)$ & $17(14-19)$ & n.s. \\
GMYC r8s & $38(30-41)$ & $15(14-16)$ & $28(25-30)$ \\
GMYC MPL & $29(27-53)$ & n.s. & $28(19-40)$ \\
GMYC chronos & n.s. & $17(14-19)$ & $63(50-67)$ \\
\hline
\end{tabular}

For COI sequences, ABGD reports the estimates for prior intraspecific divergence $>1.5 \%$; for ITS1, ABGD provided consistent results of 14 across all the prior intraspecific divergences. Estimated values of potential cryptic species are reported for PTP (PTP ML = from Maximum Likelihood solutions, PTP BI = from Bayesian solutions) and the $95 \%$ confidence interval for GMYC, with chronograms obtained from BEAST, PhyML + r8s, PhyML + MPL, and PhyML + chronos. NA means that the test cannot be performed on the dataset; n.s. means that the test failed in providing any evidence of independently evolving entities

results, despite differences in the tree topologies that were obtained from the different phylogenetic reconstructions, would enhance the reliability of the results. For the statistical models, we used all the variables expressing count data (e.g. number of individuals and number of unique sequences) with their log-transformed values. Pagel's lambda and Blomberg's K values were estimated with the R package phytools $\mathrm{V}$ 0.4-31 (Revell, 2012); PGLS models were performed in the R package caper $\mathrm{v}$ 0.5.2 (Orme et al., 2013).

Using the same methods, we also tested whether a phylogenetic signal was present in the species complex in (1) habitat type (coastal waters vs. continental saltwater bodies), (2) body length (from measurements available in the original descriptions of the species), (3) genome size (as reported in Stelzer et al., 2011), (4) geographic range (as number of continents where the species has been found), (5) genetic diversity (as number of unique sequences relative to the number of analysed individuals), and (6) number of occurrences.

\section{Results}

Out of the 1273 isolates used in this study for COI and ITS1: the alignment for COI included 1223 isolates,
Fig. 2 Phylogenetic relationships of the 45 ITS1 haplotypes from 481 individuals in the Brachionus plicatilis species complex, according to Bayesian inference reconstructions. The consensus of 8000 sampled trees from Bayesian analysis run in BEAST is shown, displaying all compatible groupings and with average branch lengths proportional to numbers of substitutions per site under a GTR $+\mathrm{I}+\mathrm{G}$ substitution model. Posterior probabilities from BEAST/support values as approximate Likelihood Ratio Test from PhyML are shown above each branch, but not for within-species branches; the '-' symbol indicates support $<0.90$ for posterior probabilities and $<0.80$ for HLR tests. The complete trees with all haplotypes names and all support values are available as Supplementary Figs. S1 and S2. The three grey circles on basal nodes indicate the three main groups known in the species complex, namely Large (L), SmallMedium (SM), and Small (SS). Clade names are according to Table 2. The number of potential independently evolving units is consistent across the different methods in DNA taxonomy (see Table 1). Pairwise uncorrected genetic distances within each species are reported as median values (range minimummaximum)

collapsed into 275 unique sequences; the alignment for ITS1 included 481 isolates, collapsed into 45 unique sequences; the concatenated alignment included 431 isolates, collapsed into 174 unique sequences.

Phylogenetic reconstructions for each marker were highly congruent for Maximum Likelihood and Bayesian Inference (Figs. 2, 3, Supplementary Figs. S1-S4). The three known major groups of L, SM, and SS clades were supported, but not always with maximum confidence (Figs. 2, 3, Supplementary Figs. S1-S4). For the combined dataset (Fig. 4, Supplementary Fig. S5), BEAST failed to converge, and values of ESS were not higher than 200 for all parameters. Thus, no reliable phylogenetic reconstruction was obtained with a Bayesian approach on the combined dataset, potentially due to the contrasting topologies of the two markers for the deeper nodes and to the mitonuclear discordance between different individuals within each species (see below), preventing convergence (Figs. 2, 3).

\section{DNA taxonomy}

DNA taxonomy tools based on the three datasets provided estimates of cryptic species ranging from 14 to 67 (Table 1). Estimates based on COI ranged from 17 to 55. The minimum estimate of 17 (provided by ABGD) was well below the range of the most conservative estimate within the potential solutions from PTP (52-55 species) and GMYC (27-53 species). Using ITS1, all the methods consistently indicated at least 14 species (Table 1; Fig. 2). The 


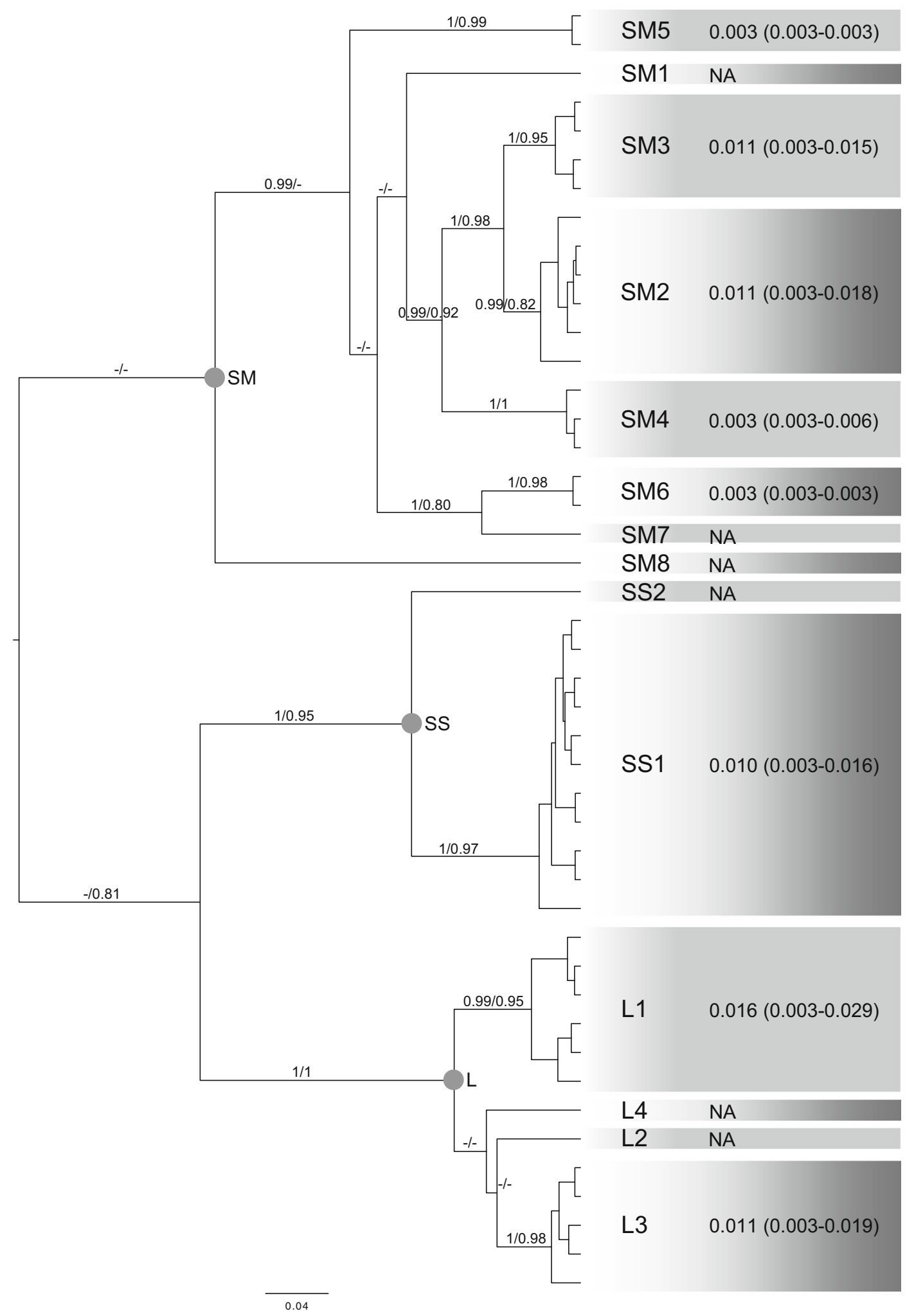




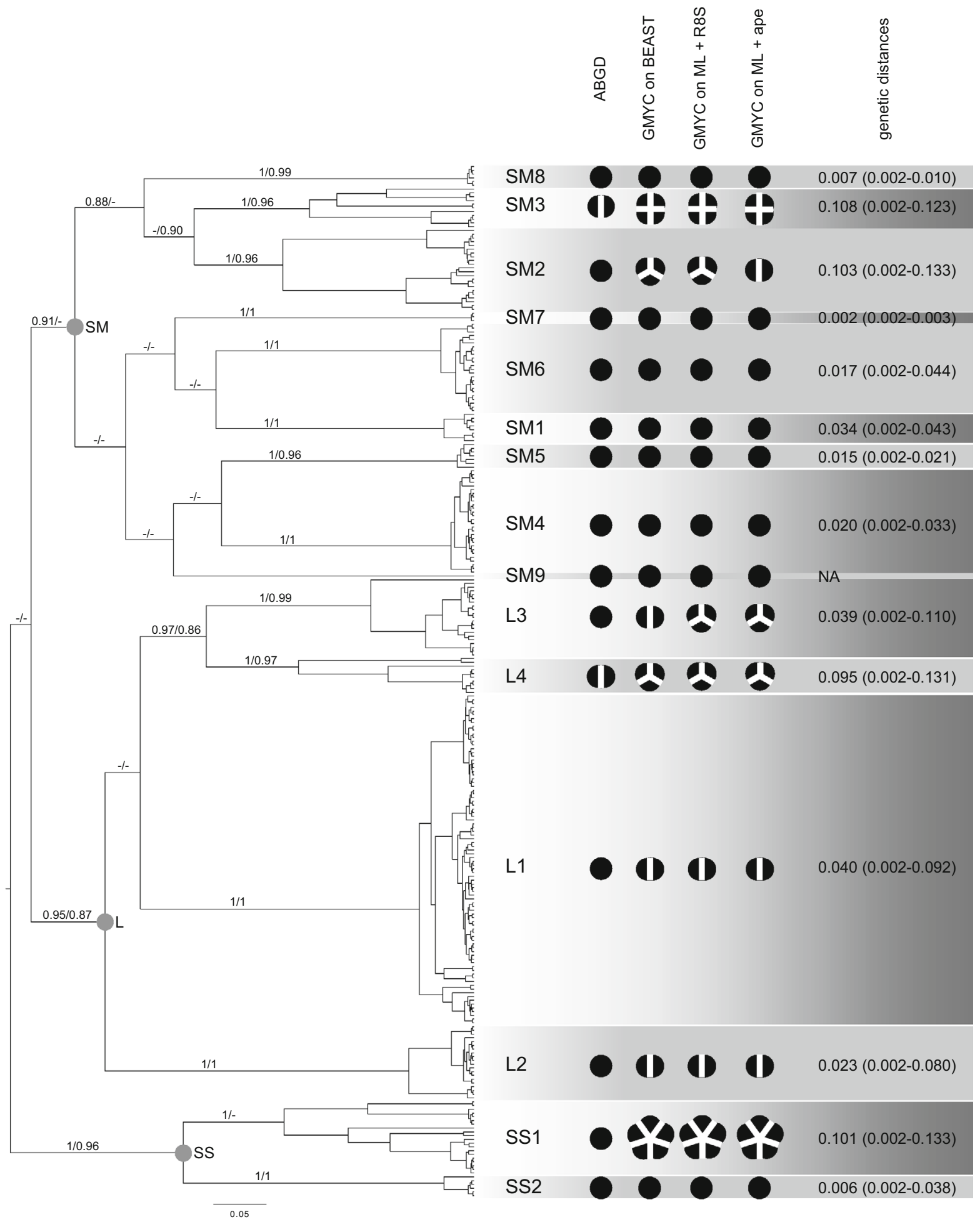


4Fig. 3 Phylogenetic relationships of the 275 COI haplotypes from 1223 individuals in the Brachionus plicatilis species complex, according to Bayesian Inference reconstructions. The consensus of 8000 sampled trees from Bayesian analysis run in BEAST is shown, displaying all compatible groupings and with average branch lengths proportional to numbers of substitutions per site under a GTR $+\mathrm{I}+\mathrm{G}$ substitution model. Posterior probabilities from BEAST/support values as approximate Likelihood Ratio Test from PhyML are shown above each branch, but not for within-species branches; the '-' symbol indicates support $<0.90$ for posterior probabilities and $<0.80$ for aLRT tests. The complete trees with all haplotypes names and all support values are available as Supplementary Figs. S3 and S4. The three grey circles on basal nodes indicate the three main groups known in the species complex, namely Large (L), Small-Medium (SM), and Small (SS). Clade names are according to Table 2. The number of potential independently evolving units within each species according to the different methods in DNA taxonomy (ABGD and GMYC on different chronograms) is reported as circles, with numbers of slices representing number of units (see Table 1). Results for PTP are not reported as this method produced an overestimation of units from the COI phylogenies (more than 50: Table 1). Pairwise uncorrected genetic distances within each species are reported as median values (range minimum-maximum)

GMYC model on ITS1 gave optimal solutions of 15 or 17 , but 14 was consistently the most conservative estimate among the equally likely solutions within the 95\% confidence interval for all the GMYC models (Table 1). For the concatenated alignment, estimates of the number of species ranged from 19 to 67 (Table 1): these results are the most variable, and thus they will not be considered further.

The most conservative estimate of 17 species from ABGD using COI sequences included all 14 species identified from ITS1, plus one species for which no ITS1 sequence was available (species SM9; Fig. 3), and two species (SM3 and L4) with two entities each instead of one (Fig. 3). The other methods provided more splits within seven of the 15 species (Fig. 3). Therefore, the most consistent number of lineages appears to be the estimate of 14 species obtained from ITS1, plus one single COI lineage for which no ITS1 sequence is available (species SM9 from Lake Turkana in Kenya). These 14(+1) potential species are also the main well-supported lineages that can be easily seen on the phylogenetic trees (Figs. 2, 3, 4), and six of them match the six species that have already been described in the genus: B. asplanchnoidis (L3), B. ibericus (SM1), B. koreanus (SM2), B. manjavacas (L2), B. plicatilis s.s. (L1), and B. rotundiformis (SS1).

In the 14 species for which both COI and ITS1 were available, no evidence was found of phylogenetic discordance between mitochondrial and nuclear phylogenies, that is of individuals harbouring COI of one species and ITS1 of another one (Fig. 5).

\section{Evidence of independent biological entities}

For COI sequences, maximum uncorrected genetic distances within the 15 putative species ranged from 0.3 to $13.3 \% \quad($ median $=3.79 \%$, mean $=3.90 \%$ ) (Fig. 3); distances between species ranged from 11.9 to $23.2 \%$ (median $=18.9 \%$, mean $=18.6 \%)$. Distances between the species of the $\mathrm{L}$ group ranged from 13.6 to $22.1 \%$, between the species of the SM group from 11.9 to $22.4 \%$, and between the species of the SS group from 14.3 to $17.3 \%$. Thus, all species of the $\mathrm{L}$ and SS group had within-species distances up to 13.1 and $13.3 \%$, respectively (Fig. 3); these values are lower than the between-species distances, meaning that a barcoding gap existed. On the other hand, two of the species in the SM group (SM4 and SM5) had within-species distances below $3.3 \%$, but betweenspecies distances ranging from 12.4 to $14.5 \%$, partially overlapping with the maximum values of the withinspecies distances, up to $13.3 \%$, in other species in other parts of the tree (i.e. B. koreanus (SM2), B. rotundiformis (SS1), and L4: Fig. 3).

For ITS1 sequences, maximum uncorrected genetic distances within the 14 putative species ranged from 0.3 to $1.9 \% \quad($ median $=0.95 \%$, mean $=0.95 \%$; Fig. 2); distances between species ranged from 2.5 to $22.0 \%$ (median $=15.6 \%$, mean $=13.9 \%)$. Distances between the species of the $\mathrm{L}$ group ranged from 2.5 to $9.5 \%$, between the species of the SM group from 3.7 to $10.6 \%$, and between the species of the SS group from 6.4 to $7.0 \%$.

The number of unique COI sequences and maximum genetic distances in COI within each species, both metrics of potential genetic diversity for each species, were significantly correlated to the number of analysed individuals (PGLS: $t_{12}=5.71, P<0.001 ; t_{12}=3.05$, $P=0.010$, respectively). The same pattern was found for ITS1 sequences, with both the number of unique sequences (PGLS: $t_{12}=4.4, P=0.001$ ) and maximum genetic distances (PGLS: $t_{6}=2.7, P=0.033$ ) related to the number of individuals. Among the analysed variables, the number of unique sequences for COI and for ITS1 and the number of individuals found in each species had a low phylogenetic signal (Fig. 4). On the other hand, the phylogenetic signal was 


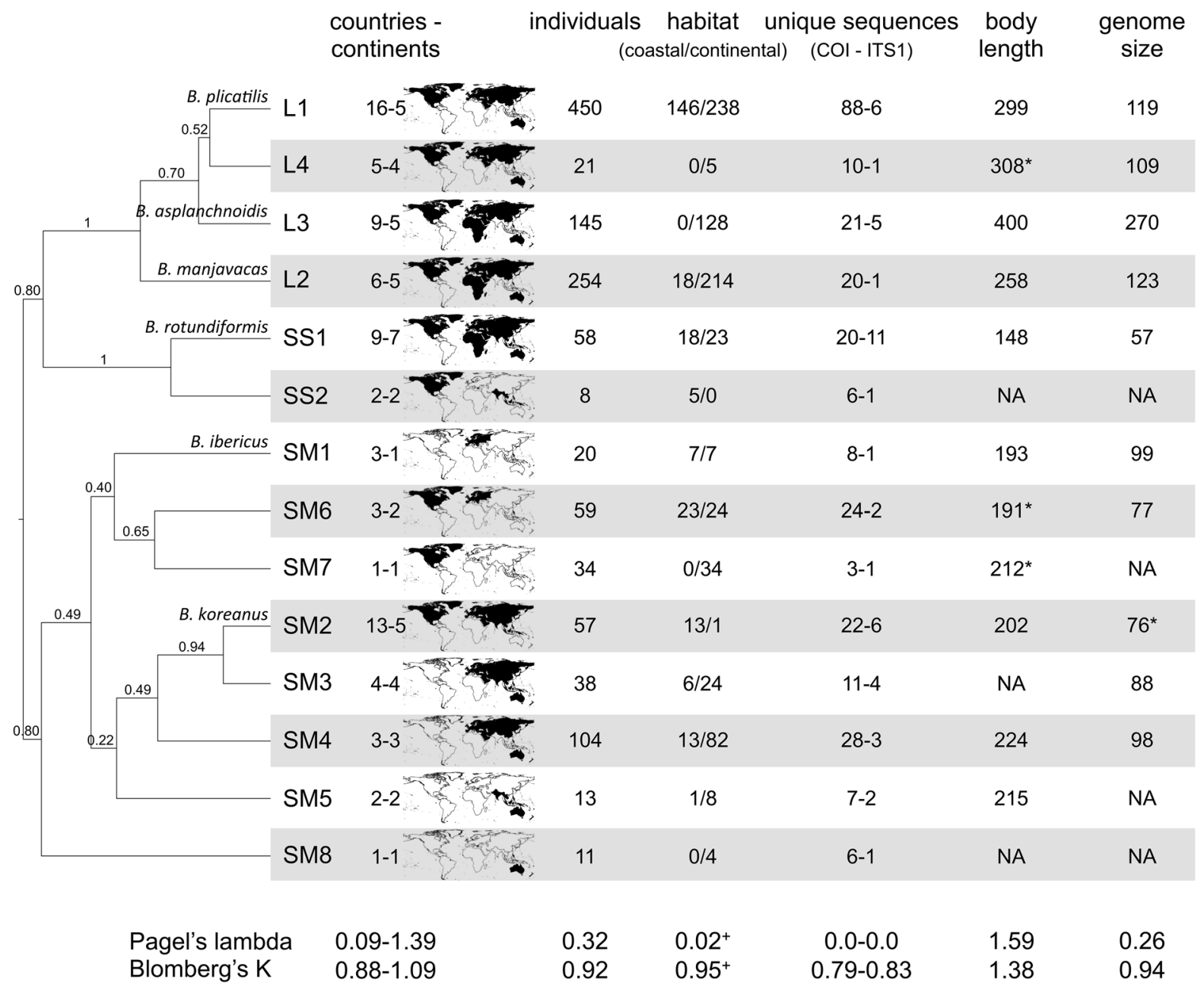

Fig. 4 Phylogenetic relationships among the 14 species of the Brachionus plicatilis species complex for which both COI and ITS1 are available. The tree was obtained from a RAxML run on combined alignments, made ultrametric with $\mathrm{r} 8 \mathrm{~s}$, and pruned to include only one random terminal per species; bootstrap supports are from 100 replicates. The name of the six described species in the complex are reported on the tree. The original tree is available as Supplementary Fig. S5. Additional information on sample size, genetic diversity, ecological, and biological traits is reported for each species; not all information is available for all sequenced individuals. Body length and genome size data

strong for the maximum genetic distances both for COI (Pagel's lambda $=2.19$, Blomberg's $\mathrm{K}=1.05$ ) and for ITS1 (Pagel's lambda $=1.97$, Blomberg's $=1.13$ ), with the species in the L group exhibiting, on average, higher diversity than the species in the SS and in the SM group.

The number of continents where each species was found had a strong phylogenetic signal (Fig. 4), with come from published literature, except for those marked with an asterisk, which were measured in this study. Maps depict the known distribution of each species at continental level (continents defined according to TDWG Level 1). Pagel's lambda and Blomberg's $\mathrm{K}$ are reported for each variable to estimate the phylogenetic signal. The symbol + for phylogenetic signal for habitat denotes that zero values were transformed to 0.00001 to avoid dealing with infinite ratios. Lambda (and K) for other variables not in figure is maximum COI genetic distances $=2.19 \quad(1.05)$ and maximum ITS1 genetic distances $=1.97(1.13)$

species of the SM group being present in a lower number of continents than species of the L or SS group. Moreover, geographic distribution, expressed as the number of continents where each species was found, was not related to the number of individuals for each species (PGLS: $t_{12}=1.23, P=0.242$ ).

Body length had a strong phylogenetic signal (Fig. 4), with species of the L group effectively larger 


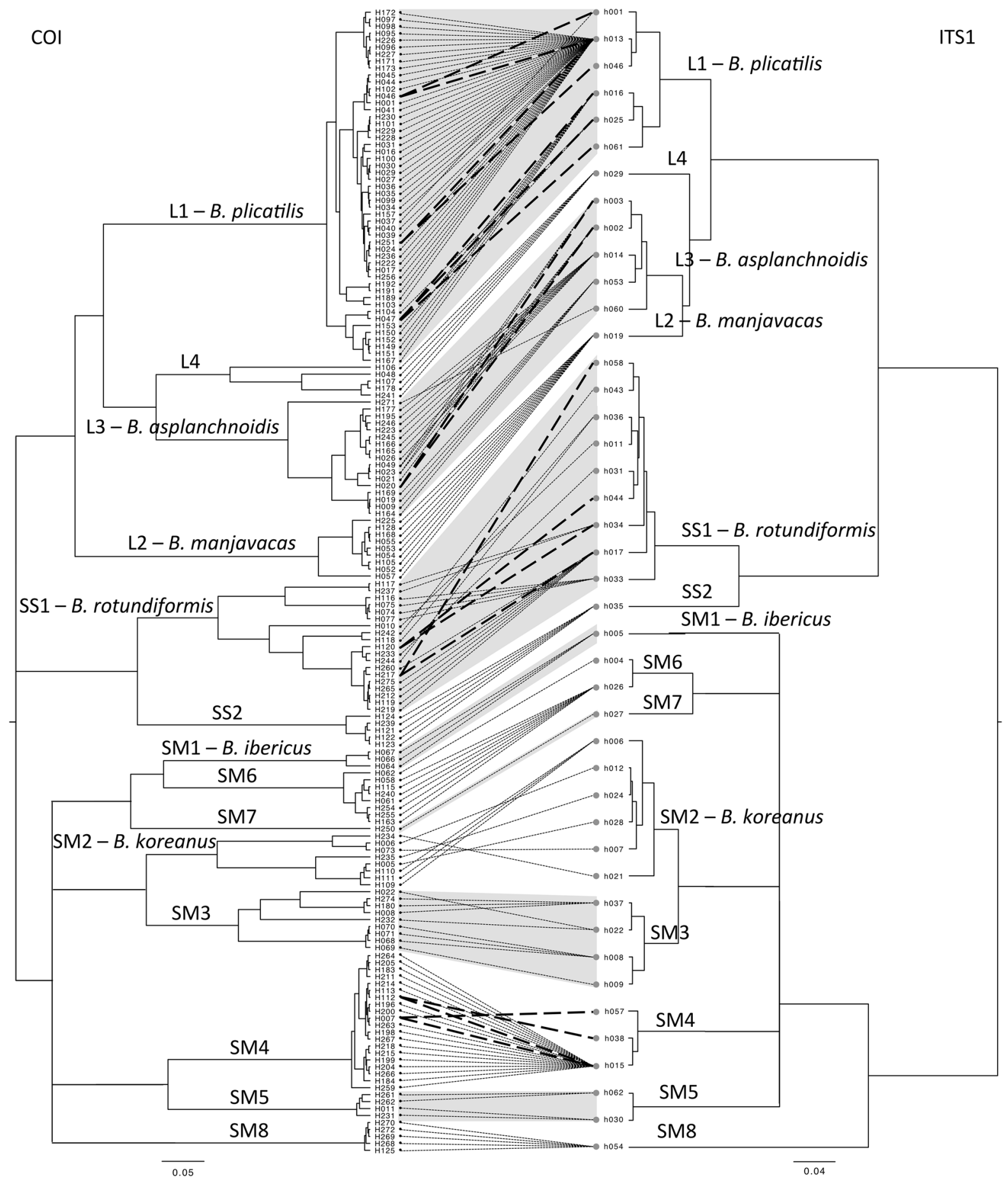

Fig. 5 Tanglegram for all individuals for which both COI (left) and ITS1 (right) were available. Each phylogeny was obtained from the complete BEAST reconstructions (Supplementary Figs. S1 and S3) pruned in order to have only unique sequences. Polytomies were enforced when the topology was not congruent with that of Fig. 4. Dashed lines connect individuals in which
COI and ITS1 co-occurred. Thick dashed lines represent instances of mitonuclear discordance (individuals sharing the same COI sequence but with different ITS1). Alternating grey and white areas under the dashed lines separate the 14 species, marked on the trees with their names 
than those of the SM group, themselves larger than those of the SS group. Body length seems to be significantly correlated to genome size (PGLS: $\left.t_{7}=5.8, P<0.001\right)$, whereas genome size does not have a strong phylogenetic signal (Fig. 4).

The results obtained on the phylogeny obtained from the combined datasets were qualitatively supported in the tests on comparative analyses using the topology of either only COI or ITS1 phylogenies (Supplementary File S2); the results on phylogenetic signals were qualitatively supported using the COI phylogeny, whereas they were not that clear when using the topology of the ITS1 phylogeny (Supplementary File S2).

\section{Discussion}

Despite the importance of the B. plicatilis species complex in basic research and aquaculture, the systematics and taxonomy of this group have remained unclear. Cryptic species complexes are, by definition, a set of closely related species that share very similar morphological traits, thus, deciphering the diversity of these complexes has been difficult because of morphological stasis (Campillo et al., 2005). The morphospecies criterion used in taxonomy-identifying groups of individuals with typical morphological characteristics distinguishable from other groups-is usually the first approach for diversity studies. However, use of morphological attributes alone to differentiate species has limitations, especially in rotifers and other microscopic animals with few morphological features (Tang et al., 2012) and phenotypic plasticity such as cyclomorphosis and inducible defences (Gilbert \& Stemberger, 1984; Sarma et al., 2011). Thus, as in the case of the B. plicatilis species complex, the use of tools from DNA taxonomy on more than one marker may be informative, adding a genealogic and phylogenetic concept to the approaches used to define species in the complex.

Overall, our extensive analyses of the genetic diversity in COI and ITS1 sequences within the B. plicatilis complex revealed, as a conservative estimate, 15 species: four belonging to the L group (B. asplanchnoidis, B. manjavacas, B. plicatilis s.s., and clade L4), two belonging to the SS group (B. rotundiformis and clade SS2), seven belonging to the SM group (B. ibericus, B. koreanus, and clades SM3-7), and two (SM8 and SM9) for which the inclusion in the SM group is suggested but needs to be confirmed. Six of these species were already described before this study, and the correspondence with the previously used names of Brachionus sp. 'Locality' for all the species is reported in Table 2. The species identified by our DNA taxonomy approach are in complete agreement with the taxa already identified by Gómez et al. (2002) and Suatoni et al. (2006).

Moreover, our study offers a basis for further analyses on the species complex, providing a phylogenetic structure for comparative studies. The phylogeny shown in Fig. 4 can be downloaded in Supplementary File S3 and from FigShare (10.6084/ m9.figshare.2077531), for further phylogenetic comparative analyses on other biological traits.

Support for species identity

We chose the most conservative estimates of species diversity in our DNA taxonomy approach to identify species. Our rationale was to avoid dividing the species complex into taxa that could not be well supported. Different approaches from DNA taxonomy

Table 2 List of the $14+1$ clades with unambiguous evidence of cryptic species in the Brachionus plicatilis species complex, and correspondence with described species and unofficial names that are used in the literature

\begin{tabular}{lll}
\hline Clade & Species & Unofficial name \\
\hline L1 & B. plicatilis & - \\
L2 & B. manjavacas & 'Manjavacas' \\
L3 & B. asplanchnoidis & 'Austria' \\
L4 & - & 'Nevada' \\
SM1 & B. ibericus & - \\
SM2 & B. koreanus & 'Cayman' \\
SM3 & - & 'Tiscar' \\
SM4 & - & 'Towerinniensis' \\
SM5 & - & 'Coyrecupiensis' \\
SM6 & - & 'Almenara' \\
SM7 & - & 'Mexico' \\
SM8 & - & 'Harvey' \\
SM9 & - & 'Turkana' \\
SS1 & B. rotundiformis & \\
SS2 & - & 'Lost'
\end{tabular}

A clear attribution of each of the 1273 isolates for these species is available in Supplementary File S1 
provided different estimates of diversity in the complex. Previous comparisons between different methods (Tang et al., 2012; Dellicour \& Flot, 2015) usually relied on smaller datasets for each species complex or on simulated data, whereas our study can be used also as a caveat for the uncertainties in phylogenetic-based approaches on DNA taxonomy from single markers. Apparently, ABGD seems to be more robust for large datasets than PTP or GMYC.

Six formally described species in the complex perfectly matched the species highlighted by ABGD, using either ITS1 or COI datasets. Two of the still unnamed species (SM3 and L4) could be unambiguously delimited as unique species with the ITS1 but not with the COI dataset, for which at least two species were found (Fig. 3). This is consistent with previous results showing that $\mathrm{COI}$ is more rapidly evolving and thus apparently showing more taxonomic diversity than other commonly used markers (Tang et al., 2012).

Uncorrected genetic distances within and between species for the two markers are rather high in comparison with what is known in other animals (Hebert et al., 2003; Pfenninger \& Schwenk, 2007). Wide variability in the thresholds for the barcoding gap is known across phyla and even within phyla, and rotifers were already known to have a COI barcoding threshold much higher than the commonly accepted 3\% (Fontaneto, 2014). The DNA taxonomy approach that we used was able to identify a clear and unambiguous barcoding gap in ITS1, with maximum genetic distances within species of $1.9 \%$ and minimum genetic distances between species of $2.5 \%$. In contrast, the situation for COI was not that clear: the maximum within-species genetic distance of $13.3 \%$ was higher than the minimum between-species genetic distance of $11.9 \%$. Thus, a strict barcoding approach in COI may be misleading if we assume the existence of 15 species in the complex. Overall, COI did not score coherently well as a marker for DNA taxonomy in this species complex, given that each approach provided different and often non-overlapping results (Table 1; Fig. 3). Previous analyses had shown that COI provided more than 15 species in the complex (e.g. Fontaneto et al., 2009; Malekzadeh-Viayeh et al., 2014). Yet, both COI and ITS1 provide congruent monophyletic lineages, at least for the 14 species with both markers available. To avoid the possibility of over-splitting the complex, we suggest use of ITS1 as a more reliable marker for DNA taxonomy in the B. plicatilis complex. Using only COI as a molecular marker will be fine to identify new individuals within the currently delimited 15 species; if COI is used to support additional species, this should always be done in addition to other approaches from morphology, physiology, ecology, or with crossmating experiments. Given that COI is more variable than ITS1, the former is still the best marker to be used for exploration of population genetic structure within species and phylogeography. Overall, some species in the complex (e.g. B. plicatilis s.s. and SM4), which are well sampled with hundreds of sequenced individuals, exhibit rather shallow phylogenetic structure, with a relatively recent least common ancestor. However, others species (e.g. B. asplanchnoidis, B. koreanus, $B$. rotundiformis, and SM3) show deep within-species genetic divergences, regardless of sample size. The reason for such differences is still unknown and deserves further investigation.

Another approach that can be used to support the existence of species is to apply the biological species concept (Mayr, 1963), which defines a species as a population or group of populations that have the potential to interbreed and produce fertile offspring. Detection of cryptic species by means of direct tests on reproductive isolation is challenging because experimental cross-mating trials in the laboratory may result in mating that would not occur in nature, as observed during the tests of reproductive isolation carried out by Suatoni et al. (2006). Nevertheless, the 14 species for which we had both COI and ITS1 from several individuals revealed absolutely no evidence of potential hybrids. That is, despite extensive geographic overlap in distribution and habitat, and therefore potential opportunities for cross-fertilisation, we found no evidence of hybrid individual with phylogenetic discordance between mitochondrial and nuclear markers (Fig. 5). This observation provides strong, indirect support for the existence of reproductive barriers acting in the field among the 14 species.

In contrast, within each of the species, we observed phylogenetic discordance in COI and ITS1 sequences between individuals. For example, some individuals that share the same COI sequence have different ITS1 sequences in B. asplanchnoidis, B. plicatilis s.s., B. rotundiformis, and SM4 (tips connected with thick dashed lines in Fig. 5). Such free segregation of markers is exactly what should be expected when 
comparing individuals of the same species and supports the idea of the $14(+1)$ species as actual arenas for recombination (Doyle, 1995; Flot et al., 2010).

The absence of hybrids in the B. plicatilis complex is in stark contrast with what is known in the $B$. calyciflorus complex, for which a high level of hybridization and mitonuclear discordance between cryptic species is present (Papakostas et al., 2016). The reasons for such differences in the level of hybridization in the two species complexes of the same genus are still unknown and deserve further investigation.

\section{Ecology and geography}

Brachionus plicatilis has traditionally been considered a cosmopolitan species found in almost any type of saline aquatic habitat. The identification of $B$.plicatilis as a species complex suggested the possibility that each cryptic species represented an independent lineage with a limited geographic distribution and a narrower ecological tolerance. This general concept has received recent support for other cryptic species groups in Rotifera (Obertegger et al., 2014; Gabaldón et al., 2016).

A detailed investigation into the geographic distribution of genetic lineages of the cosmopolitan cryptic species B. plicatilis s.s. revealed existence of four clades associated to four geographic regions, one in North America, two in Europe, and one in Australia, with a high amount of variability in genetic distance explained by geographic distance $\left(R^{2}=0.91\right)$ (Mills et al., 2007). Such results reinforced the idea that each member of the complex may have a limited geographic distribution. Yet, our results indicate that most species within the complex are indeed cosmopolitan: all the species with at least 140 isolates sampled were found in five or more continents (Fig. 4). Three species were found in one continent only, but this could be due to their small sample sizes $(<34$ individuals). However, two species with very small sample sizes (SS2 with 8 and SM5 with 13 individuals) were found in two continents, and the most widespread species, B. rotundiformis found in 7 continents, had a relatively low sample size of 58 (Fig. 4). Being present in more than two continents cannot be used as an argument towards limited geographic distribution, even if some geographical structure may exist at the regional level; a pattern that was not specifically explored in this study. Yet, distributional patterns and processes in microscopic animals are known to act at different spatial scales than in macroscopic organisms (Fontaneto, 2011), with rotifers having a larger distribution at the global scale than macroscopic animals (Fontaneto et al., 2006; Segers \& De Smet, 2008), together with strong spatial patterns in the structure of genetic diversity at the local and regional scale (De Meester et al., 2002; Mills et al., 2007).

Regarding ecological correlates of diversity in the B. plicatilis complex, our results did not clearly support the concept of niche conservatism (Wiens \& Graham, 2005). In several species of the complex, the preference for either coastal or inland habitats seems to have a clear signal from the visual inspection of the tree (Fig. 4), but the explicit tests for phylogenetic signal did not show such evidence. The co-occurrence of three or more species of the B. plicatilis complex in the same pond (Ortells et al., 2003) seems to be in contrast with niche conservatism given that niche conservatism would prevent co-occurrence of closely related species. In support of a potential mechanism allowing co-occurrence even in case of strong niche conservatism, seasonal species replacement has been observed (Gómez et al., 1995). A detailed exploration of ecological correlates of diversity should be performed on samples collected with this idea in mind in order to minimise potential sampling bias, which was difficult to control for in our general analysis.

Body length and genome size

One of the first indications of phenotypic differences among strains, supporting existence of cryptic species, was due to differences in body length. Three main groups were identified based on this criterion: large (L), medium (SM), and small (SS), which have already received support from other phylogenetic studies (Gómez et al., 2002; Suatoni et al., 2006). Our phylogenetic reconstruction confirmed these groups to be monophyletic and provided evidence of a strong phylogenetic signal in body length, which is the trait with the highest signal among the ones we tested: closely related species are indeed similar in body length and, with Pagel's lambda and Blomberg's K higher than unity, they are even more similar than expected under a Brownian motion model of trait evolution (Kamilar \& Cooper, 2013). 
Body length seems to be related to genome size; yet, our approach did not include within-species variability in body length and genome size, which is known to be large for example in B. asplanchnoidis (Stelzer et al., 2011). Using only mean values for each species may be why our results conflict with the lack of correlation found by Stelzer et al. (2011). Thus, the relationship between genome size and phenotypic traits should be explored in more detail: e.g. including additional traits such as egg size (as was done by Stelzer et al., 2011) or trophi size, and expanding the dataset for the analyses using an approach that is able to disentangle the within-species and the betweenspecies contribution to the variability. Such analyses will surely provide interesting inferences on the evolutionary trajectories of phenotypic differences in rotifers and in animals in general.

\section{Conclusions}

This study represents the first of its kind to employ a worldwide effort of researchers to unravel the phylogeny of a cryptic species complex. This achievement was possible due to several factors: years of studies on a species with commercial importance, its ease of culture, and its importance as a model system for other avenues of research. If other rotifer species possess a similarly high level of genetic diversity, our taxonomic knowledge of this phylum is minuscule.

We can also infer that the same situation could be found in most microscopic animals for which few resources or little effort has been invested in taxonomy and for which morphological features are not readily discernable. Thus, we suggest that diversity in microscopic animals is higher than currently estimated (Appeltans et al., 2012; Curini-Galletti et al., 2012). Such revolution may greatly affect estimates of species richness (Costello et al., 2012).

Acknowledgments We acknowledge support from the staff of the Department of Biological Sciences at the University of Texas at El Paso, especially B. Smith, T. Valenzuela, L. and L. Hamden. Two anonymous reviewers provided useful comments to improve an earlier draft of the manuscript. Funding was provided by UTEP's Office of Research and Sponsored Projects, College of Science, Department of Biological Sciences, NSF DEB 1257068 (E. J. Walsh) and NSF DEB 1257116 (R. L. Wallace).

\section{References}

Appeltans, W., S. T. Ahyong, G. Anderson, M. V. Angel, T. Artois, N. Bailly, R. Bamber, A. Barber, I. Bartsch, A. Berta, M. Błażewicz-Paszkowycz, P. Bock, G. Boxshall, C. B. Boyko, S. Nunes Brandao, R. A. Bray, N. L. Bruce, S. D. Cairns, T.-Y. Chan, L. Cheng, A. G. Collins, T. Cribb, M. Curini-Galletti, F. Dahdouh-Guebas, P. J. F. Davie, M. N. Dawson, O. De Clerck, W. Decock, S. De Grave, N. J. de Voogd, D. P. Domning, C. C. Emig, C. Erséus, W. Eschmeyer, K. Fauchald, D. G. Fautin, S. W. Feist, C. H. J. M. Fransen, H. Furuya, O. Garcia-Alvarez, S. Gerken, D. Gibson, A. Gittenberger, S. Gofas, L. Gómez-Daglio, D. P. Gordon, M. D. Guiry, F. Hernandez, B. W. Hoeksema, R. R. Hopcroft, D. Jaume, P. Kirk, N. Koedam, S. Koenemann, J. B. Kolb, R. M. Kristensen, A. Kroh, G. Lambert, D. B. Lazarus, R. Lemaitre, M. Longshaw, J. Lowry, E. Macpherson, L. P. Madin, C. Mah, G. Mapstone, P. A. McLaughlin, J. Mees, K. Meland, C. G. Messing, C. E. Mills, T. N. Molodtsova, R. Mooi, B. Neuhaus, P. K. L. $\mathrm{Ng}$, C. Nielsen, J. Norenburg, D. M. Opresko, M. Osawa, G. Paulay, W. Perrin, J. F. Pilger, G. C. B. Poore, P. Pugh, G. B. Read, J. D. Reimer, M. Rius, R. M. Rocha, J. I. SaizSalinas, V. Scarabino, B. Schierwater, A. Schmidt-Rhaesa, K. E. Schnabel, M. Schotte, P. Schuchert, E. Schwabe, H. Segers, C. Self-Sullivan, N. Shenkar, V. Siegel, W. Sterrer, S. Stöhr, B. Swalla, M. L. Tasker, E. V. Thuesen, T. Timm, M. A. Todaro, X. Turon, S. Tyler, P. Uetz, J. van der Land, B. Vanhoorne, L. P. van Ofwegen, R. W. M. van Soest, J. Vanaverbeke, G. Walker-Smith, T. C. Walter, A. Warren, G. C. Williams, S. P. Wilson \& M. J. Costello, 2012. The magnitude of global marine species diversity. Current Biology 22: 2189-2202.

Alcántara-Rodríguez, J. A., J. Ciros-Pérez, E. Ortega-Mayagoitia, C. R. Serranía-Soto \& E. Piedra-Ibarra, 2012. Local adaptation in populations of a Brachionus group plicatilis cryptic species inhabiting three deep crater lakes in Central Mexico. Freshwater Biology 57: 728-740.

Bickford, D., D. J. Lohman, N. S. Sodhi, P. K. Ng, R. Meier, K. Winker, K. K. Ingram \& I. Das, 2007. Cryptic species as a window on diversity and conservation. Trends in Ecology and Evolution 22: 148-155.

Blomberg, S. P., T. Garland Jr \& A. R. Ives, 2003. Testing for phylogenetic signal in comparative data: Behavioral traits are more labile. Evolution 57: 717-745.

Brummitt, R. K. 2001. World Geographical Scheme for Recording Plant Distributions, 2 edn. International Working Group on Taxonomic Databases For Plant Sciences (TDWG).

Butlin, R., J. Bridle \& D. Schluter, 2009. Speciation and Patterns of Diversity. Cambridge University Press, Cambridge.

Campillo, S., E. M. García-Roger, D. Martínez-Torres \& M. Serra, 2005. Morphological stasis of two species belonging to the L-morphotype in the Brachionus plicatilis species complex. Hydrobiologia 546: 181-187.

Campillo, S., E. M. García-Roger, M. J. Carmona, A. Gómez \& M. Serra, 2009. Selection on life-history traits and genetic population divergence in rotifers. Journal of Evolutionary Biology 22: 2542-2553. 
Carmona, M. J., N. Dimas-Flores, E. M. García-Roger \& M. Serra, 2009. Selection of low investment in sex in a cyclically parthenogenetic rotifer. Journal of Evolutionary Biology 22: 1975-1983.

Charin, N. N., 1947. O novom vide kolovratki is roda Brachionus. Doklady Akademii Nauk SSSR 56: 107-108.

Ciros-Pérez, J., A. Gómez \& M. Serra, 2001a. On the taxonomy of three sympatric sibling species of the Brachionus plicatilis (Rotifera) complex from Spain, with the description of B. ibericus n. sp. Journal of Plankton Research 23: 1311-1328.

Ciros-Pérez, J., M. J. Carmona \& M. Serra, 2001b. Resource competition between sympatric sibling rotifer species. Limnology and Oceanography 46: 1511-1523.

Ciros-Pérez, J., M. J. Carmona, S. Lapesa \& M. Serra, 2004. Predation as a factor mediating resource competition among rotifer sibling species. Limnology and Oceanography 49: 40-50.

Ciros-Pérez, J., E. Ortega-Mayagoitia \& J. Alcocer, 2015. The role of ecophysiological and behavioral traits in structuring the zooplankton assemblage in a deep, oligotrophic, tropical lake. Limnology and Oceanography 60: 2158-2172.

Costello, M. J., S. Wilson \& B. Houlding, 2012. Predicting total global species richness using rates of species description and estimates of taxonomic effort. Systematic Biology 61: 871-883.

Curini-Galletti, M., T. Artois, V. Delogu, W. H. De Smet, D. Fontaneto, U. Jondelius, F. Leasi, A. Martínez, I. MeyerWachsmuth, K. S. Nilsson, P. Tongiorgi, K. Worsaae \& M. A. Todaro, 2012. Patterns of diversity in soft-bodied meiofauna: dispersal ability and body size matter. PloS One 7: e33801.

Dahms, H. U., A. Hagiwara \& J. S. Lee, 2011. Ecotoxicology, ecophysiology, and mechanistic studies with rotifers. Aquatic Toxicology 101: 1-12.

De Meester, L., A. Gómez, B. Okamura \& K. Schwenk, 2002. The Monopolization Hypothesis and the dispersal-gene flow paradox in aquatic organisms. Acta Oecologica 23: 121-135.

Dellicour, S. \& J.-F. Flot, 2015. Delimiting species-poor data sets using single molecular markers: a study of barcode gaps, haplowebs and GMYC. Systematic Biology 64: 900-908.

Doyle, J. J., 1995. The irrelevance of allele tree topologies for species delimitation, and a non-topological alternative. Systematic Botany 20: 574-588.

Drummond, A. J., M. A. Suchard, D. Xie \& A. Rambaut, 2012. Bayesian phylogenetics with BEAUti and the BEAST 1.7. Molecular Biology and Evolution 29: 1969-1973.

Ezard, T. H. G., T. Fujisawa \& T. G. Barraclough, 2009. splits: SPecies' LImits by Threshold Statistics. http://R-Forge.Rproject.org/projects/splits/.

Flot, J.-F., A. Couloux \& S. Tillier, 2010. Haplowebs as a graphical tool for delimiting species: a revival of Doyle's field for recombination approach and its application to the coral genus Pocillopora in Clipperton. BMC Evolutionary Biology 10: 372.

Fontaneto, D., 2011. Biogeography of Microscopic Organisms: is Everything Small Everywhere? Cambridge University Press, Cambridge.
Fontaneto, D., 2014. Molecular phylogenies as a tool to understand diversity in rotifers. International Review of Hydrobiology 99: 178-187.

Fontaneto, D., G. F. Ficetola, R. Ambrosini \& C. Ricci, 2006. Patterns of diversity in microscopic animals: are they comparable to those in protists or in larger animals? Global Ecology and Biogeography 15: 153-162.

Fontaneto, D., I. Giordani, G. Melone \& M. Serra, 2007. Disentangling the morphological stasis in two rotifer species of the Brachionus plicatilis species complex. Hydrobiologia 583: 297-307.

Fontaneto, D., M. Kaya, E. A. Herniou \& T. G. Barraclough, 2009. Extreme levels of hidden diversity in microscopic animals (Rotifera) revealed by DNA taxonomy. Molecular Phylogenetics and Evolution 53: 182-189.

Fontaneto, D., C. Q. Tang, U. Obertegger, F. Leasi F. \& T. G. Barraclough, 2012. Different diversification rates between sexual and asexual organisms. Evolutionary Biology 39: 262-270

Fontaneto, D., J.-F. Flot \& C. Q. Tang, 2015. Guidelines for DNA taxonomy with a focus on the meiofauna. Marine Biodiversity 45: 433-451.

Fujisawa, T. \& T. G. Barraclough, 2013. Delimiting species using single-locus data and the generalized mixed Yule coalescent (GMYC) approach: a revised method and evaluation on simulated datasets. Systematic Biology 62: 707-724.

Fukusho, K., 1983. Present status and problems in culture of the rotifer Brachionus plicatilis for fry production of marine fishes in Japan. In Hector, R. (ed.), Symposium Internacionale de Aquaculture, Coquimbo: 361-374

Fu, Y., K. Hirayama \& Y. Natsukari, 1991a. Morphological differences between two types of the rotifer Brachionus plicatilis O.F. Muller. Journal of Experimental Marine Biology and Ecology 151: 29-41.

Fu, Y., K. Hirayama \& Y. Natsukari, 1991b. Genetic divergence between $\mathrm{S}$ and $\mathrm{L}$ type strains of the rotifer Brachionus plicatilis O.F. Muller. Journal of Experimental Marine Biology and Ecology 151: 43-56.

Fu, Y., A. Hagiwara \& K. Hirayama, 1993. Crossing between seven strains of the rotifer Brachionus plicatilis. Nippon Suisan Gakkaishi 59: 2009-2016.

Gabaldón, C., M. J. Carmona, J. Montero-Pau \& M. Serra, 2015. Long-term competitive dynamics of two cryptic rotifer species: diapause and fluctuating conditions. PloS One 10: e0124406.

Gabaldón, C., D. Fontaneto, J. Montero-Pau, M. J. Carmona \& M. Serra, 2016, Ecological differentiation in cryptic rotifer species: what wecan learn from the B. plicatilis complex. Hydrobiologia. doi:10.1007/s10750-016-2723-9.

Garamszegi, L. Z., 2014. Modern Phylogenetic Comparative Methods and Their Application in Evolutionary Biology. Springer, Berlin.

García-Morales, A. E. \& M. Elías-Gutiérrez, 2013. DNA barcoding of freshwater Rotifera in Mexico: Evidence of cryptic speciation in common rotifers. Molecular Ecology Resources 13: 1097-1107.

Gilbert, J. J. \& R. S. Stemberger, 1984. Asplanchna-induced polymorphism in the rotifer Keratella slacki. Limnology and Oceanography 29: 1309-1316. 
Gómez, A. \& M. Serra, 1995. Behavioral reproductive isolation among sympatric strains of Brachionus plicatilis Müller 1786: insights into the status of this taxonomic species. Hydrobiologia 313: 111-119.

Gómez, A. \& T. W. Snell, 1996. Sibling species in the Brachionus plicatilis species complex. Journal of Evolutionary Biology 9: 953-964.

Gómez, A., M. Temprano \& M. Serra, 1995. Ecological genetics of a cyclical parthenogen in temporary habitats. Journal of Evolutionary Biology 8: 601-622.

Gómez, A., G. R. Carvalho \& D. H. Lunt, 2000. Phylogeography and regional endemism of a passively dispersing zooplankter: mitochondrial DNA variation in rotifer resting egg banks. Proceedings of the Royal Society of London B: Biological Sciences 267: 2189-2197.

Gómez, A., M. Serra, G. R. Carvalho \& D. H. Lunt, 2002. Speciation in ancient cryptic species complexes: evidence from the molecular phylogeny of Brachionus plicatilis (Rotifera). Evolution 56: 1431-1444.

Gómez, A., J. Montero-Pau, D. H. Lunt, M. Serra \& S. Campillo, 2007. Persistent genetic signatures of colonization in Brachionus manjavacas rotifers in the Iberian Peninsula. Molecular Ecology 16: 3228-3240.

Guidon, S. \& O. Gascuel, 2003. A simple, fast, and accurate algorithm to estimate large phylogenies by maximum likelihood. Systematic Biology 52: 696-704.

Hebert, P. D. N., A. Cywinska, S. L. Ball \& J. R. DeWaard, 2003. Biological identifications through DNA barcodes. Proceedings of the Royal Society of London B: Biological Sciences 270: 313-321.

Hwang, D. S., H. U. Dahms, H. G. Park \& J. S. Lee, 2013. A new intertidal Brachionus and intrageneric phylogenetic relationships among Brachionus as revealed by allometry and CO1-ITS1 gene analysis. Zoological Studies 52: 1-10.

Jersabek, C. D. \& E. Bolortsetseg, 2010. Mongolian rotifers (Rotifera, Monogononta)-a checklist with annotations on global distribution and autecology. Proceedings of the Academy of Natural Sciences of Philadelphia 159: 119-168.

Kamilar, J. M. \& N. Cooper, 2013. Phylogenetic signal in primate behaviour, ecology and life history. Philosophical Transactions of the Royal Society B 368: 20120341.

Katoh, K., G. Asimenos \& H. Toh, 2009. Multiple alignment of DNA sequences with MAFFT. Methods in Molecular Biology 537: 39-64.

Keane, T. M., C. J. Creevey, M. M. Pentony, T. J. Naughton \& J. O. Mclnerney, 2006. Assessment of methods for amino acid matrix selection and their use on empirical data shows that ad hoc assumptions for choice of matrix are not justified. BMC Evolutionary Biology 6: 29.

King, C. E. \& Y. Zhao, 1987. Coexistence of rotifer (Brachionus plicatilis) clones in Soda Lake, Nevada. Hydrobiologia 147: 57-64.

Knowlton, N., 1993. Sibling species in the sea. Annual Review of Ecology and Systematics 24: 189-216.

Kutikova, L.A., 1970 Rotifer Fauna USSR. Fauna USSR. 104. Leningrad: Akademii Nauk SSSR

Lowe, C. D., S. J. Kemp, A. D. Bates \& D. J. S. Montagnes, 2005. Evidence that the rotifer Brachionus plicatilis is not an osmoconformer. Marine Biology 146: 923-929.
Lubzens, E. \& O. Zmora, 2003. Production and nutritional value of rotifers. In McEvoy, L. A. (ed.), Live Feeds in Marine Aquaculture. Blackwell, Oxford: 17-64.

Malekzadeh-Viayeh, R., R. Pak-Tarmani, N. Rostamkhani \& D. Fontaneto, 2014. Diversity of the rotifer Brachionus plicatilis species complex (Rotifera: Monogononta) in Iran through integrative taxonomy. Zoological Journal of the Linnean Society 170: 233-244.

Mayr, E., 1963. Animal Species and Evolution. Belknap Press of Harvard University Press, Cambridge.

Mills, S., A. Gómez \& D. H. Lunt, 2007. Global isolation by distance despite strong regional phylogeography in a small metazoan. BMC Evolutionary Biology 7: 225.

Montero-Pau, J., E. Ramos-Rodríguez, M. Serra \& A. Gómez, 2011. Long-term coexistence of rotifer cryptic species. PloS ONE 6: e21530.

Müller, O. F., 1786. Animacula infusoria fluviatilia et marina, quae detexit, systematice descripsit et ad vivum delineari curavit. Havniae [Copenhagen] et Lipsiae [Leipzig]: cura Othonis Fabricii, typis Nicolai Mölleri.

Münkemüller, T., S. Lavergne, B. Bzeznik, S. Dray, T. Jombart, K. Schiffers \& W. Thuiller, 2012. How to measure and test phylogenetic signal. Methods in Ecology and Evolution 3: $743-756$.

Obertegger, U., G. Flaim \& D. Fontaneto, 2014. Cryptic diversity within the rotifer Polyarthra dolichoptera along an altitudinal gradient. Freshwater Biology 59: 2413-2427.

Oogami, H., 1976. On the morphology of Brachionus plicatilis. Newsletter from Izu Branch, Shizuoka Prefectural Fisheries Research Center 184: 2-5.

Orme, C. D. L., R. Freckleton, G. Thomas, T. Petzoldt, S. Fritz, N. Isaac, W. Pearse, 2013. Caper: comparative analyses of phylogenetics and evolution in R. R package version 0.5.2. http://CRAN.R-project.org/package=caper.

Ortells, R., T. W. Snell, A. Gómez \& M. Serra, 2000. Patterns of genetic differentiation in resting egg banks of a rotifer species complex in Spain. Archiv für Hydrobiologie 149: 529-551.

Ortells, R., A. Gómez \& M. Serra, 2003. Coexistence of cryptic rotifer species: ecological and genetic characterisation of Brachionus plicatilis. Freshwater Biology 48: 2194-2202.

Pagel, M., 1999. Inferring the historical patterns of biological evolution. Nature 401: 877-884.

Papakostas, S., E. Michaloudi, K. Proios, M. Brehm, L. Verhage, J. Rota, C. Pena, G. Stamou, V. L. Pritchard, D. Fontaneto \& S. A. J. Declerck, 2016. Integrative taxonomy recognizes evolutionary units despite widespread mitonuclear discordance: evidence from a rotifer cryptic species complex. Systematic Biology. doi:10.1093/sysbio/syw016.

Paradis, E., J. Claude \& K. Strimmer, 2004. APE: analyses of phylogenetics and evolution in $\mathrm{R}$ language. Bioinformatics 20: $289-290$.

Pfenninger, M. \& K. Schwenk, 2007. Cryptic animal species are homogeneously distributed among taxa and biogeographical regions. BMC Evolutionary Biology 7: 121.

Puillandre, N., A. Lambert, S. Brouillet \& G. Achaz, 2012. ABGD, automatic barcode gap discovery for primary species delimitation. Molecular Ecology 21: 1864-1877.

R Core Team, 2014. R: a Language and Environment for Statistical Computing. R Core Team. R Foundation for Statistical Computing, Vienna 
Rambaut, A., M. A. Suchard, D. Xie \& A. J. Drummond, 2013. Tracer v1.5. http://beast.bio.ed.ac.uk/tracer.

Revell, L. J., 2012. phytools: an R package for phylogenetic comparative biology (and other things). Methods in Ecology and Evolution 3: 217-223.

Rumengan, I. F. M., H. Kayano \& K. Hirayama, 1991. Karyotypes of S and L type rotifers Brachionus plicatilis OF Müller. Journal of Experimental Marine Biology and Ecology 154: 171-176.

Rumengan, I. F. M., Y. Fu, H. Kayano \& K. Hirayama, 1993. Chromosomes and isozymes of hypotriploid strains of the rotifer Brachionus plicatilis. Hydrobiologia 255: 213-217.

Sanderson, M. J., 2003. r8 s: inferring absolute rates of molecular evolution and divergence times in the absence of a molecular clock. Bioinformatics 19: 301-302.

Sarma, S. S. S., R. A. L. Resendiz \& S. Nandini, 2011. Morphometric and demographic responses of brachionid prey (Brachionus calyciflorus Pallas and Plationus macracanthus (Daday)) in the presence of different densities of the predator Asplanchna brightwellii (Rotifera: Asplanchnidae). Hydrobiologia 662: 179-187.

Segers, H., 1995. Nomenclatural consequences of some recent studies on Brachionus plicatilis (Rotifera, Brachionidae). Hydrobiologia 313(314): 121-122.

Segers, H. \& W. H. De Smet, 2008. Diversity and endemism in Rotifera: a review, and Keratella Bory de St Vincent. Biodiversity and Conservation 17: 303-316.

Serra, M. \& M. R. Miracle, 1983. Biometric analysis of Brachionus plicatilis ecotypes from Spanish lagoons. Hydrobiologia 104: 279-291.

Serra, M. \& M. R. Miracle, 1987. Biometric variation in three strains of Brachionus plicatilis as a direct response to abiotic variables. Hydrobiologia 147: 83-89.

Serra, M., A. Gómez \& M. J. Carmona, 1998. Ecological genetics of Brachionus sympatric sibling species. Hydrobiologia 387: 373-384.

Serrano, L., M. R. Miracle \& M. Serra, 1986. Differential response of Brachionus plicatilis (Rotifera) ecotypes to various insecticides. Journal of Environmental Biology 7: 259-275.

Serrano, L., M. Serra \& M. R. Miracle, 1989. Size variation in Brachionus plicatilis resting eggs. Hydrobiologia 186(187): 381-386.

Snell, T. W., 1989. Systematics, reproductive isolation and species boundaries in rotifers. Hydrobiologia 186(187): 299-310.

Snell, T. W., 1998. Chemical ecology of rotifers. Hydrobiologia 387(388): 267-276.

Snell, T. W. \& K. Carrillo, 1984. Body size variation among strains of the rotifer Brachionus plicatilis. Aquaculture 37: 359-367.

Snell, T. W. \& C. A. Hawkinson, 1983. Behavioral reproductive isolation among populations of the rotifer Brachionus plicatilis. Evolution 37: 1294-1305.

Snell, T. W. \& G. Persoone, 1989. Acute toxicity bioassays using rotifers. I. A test for brackish and marine environments with Brachionus plicatilis. Aquatic Toxicology 14: 65-80.

Snell, T. W., R. K. Johnston, K. E. Gribble \& D. B. Mark Welch, 2015. Rotifers as experimental tools for investigating aging. Invertebrate Reproduction \& Development 59: 5-10.

Stamatakis, A., 2014. RAxML version 8: a tool for phylogenetic analysis and post-analysis of large phylogenies. Bioinformatics 30: 1312-1313.

Stelzer, C.-P., S. Riss \& P. Stadler, 2011. Genome size evolution at the speciation level: the cryptic species complex Brachionus plicatilis (Rotifera). BMC Evolutionary Biology 11: 90.

Suatoni, E., S. Vicario, S. Rice, T. Snell \& A. Caccone, 2006. An analysis of species boundaries and biogeographic patterns in a cryptic species complex: the rotifer-Brachionus plicatilis. Molecular Phylogenetics and Evolution 41: 86-98.

Tang, C. Q., F. Leasi, U. Obertegger, A. Kieneke, T. G. Barradough \& D. Fontaneto, 2012. The widely used small subunit $18 \mathrm{~S}$ rDNA molecule greatly underestimates true diversity in biodiversity surveys of the meiofauna. Proceedings of the National Academy of Sciences 109: 16208-16212.

Tang, C. Q., U. Obertegger, D. Fontaneto \& T. G. Barraclough, 2014a. Sexual species are separated by larger genetic gaps than asexual species in rotifers. Evolution 68: 2901-2916.

Tang, C. Q., A. Humphreys, D. Fontaneto \& T. G. Barraclough, 2014b. Effects of phylogenetic reconstruction method on the robustness of species delimitation using single locus data. Methods in Ecology and Evolution 5: 1086-1094.

Trontelj, P. \& C. Fiser, 2009. Cryptic species diversity should not be trivialised. Systematics and Biodiversity 7: 1-3.

Tschugunoff, N. L., 1921. Über das Plankton des nördlichen Teiles des Kaspisees. Raboty Volzhskoj Biologicheskoj Stancii, Saratov 6: 159-162.

Wallace, R. L., T. W. Snell, C. Ricci \& T. Nogrady, 2006. Rotifera. Vol. 1. Biology, ecology and systematics. In Dumont, H. J. F. (eds), Guides to the Identification of the Microinvertebrates of the Continental Waters of the World, Vol. 23, 2nd ed. Ghent, Kenobi Productions: 1-299.

Watanabe, T., C. Kitajima \& S. Fujita, 1983. Nutritional values of live organisms used in Japan for mass propagation of fish: a review. Aquaculture 34: 115-143.

Wiens, J. J. \& C. H. Graham, 2005. Niche conservatism: integrating evolution, ecology, and conservation biology. Annual Review of Ecology, Evolution, and Systematics 36: 519-539.

Xiang, X. L., Y. L. Xi, X. L. Wen, G. Zhang, J. X. Wang \& K. $\mathrm{Hu}, 2011$. Genetic differentiation and phylogeographical structure of the Brachionus calyciflorus complex in eastern China. Molecular Ecology 20: 3027-3044.

Zhang, J., P. Kapli, P. Pavlidis \& A. Stamatakis, 2013. A general species delimitation method with applications to phylogenetic placements. Bioinformatics 29: 2869-2876. 